\title{
Correction to: Technical and clinical validation of commercial automated volumetric MRI tools for dementia diagnosis-a systematic review
}

\author{
Hugh G. Pemberton ${ }^{1,2,3} \cdot$ Lara A. M. Zaki $\cdot$ Olivia Goodkin $^{1,2} \cdot$ Ravi K. Das $^{5} \cdot$ Rebecca M. E. Steketee $^{4}$. \\ Frederik Barkhof ${ }^{1,2,6} \cdot$ Meike W. Vernooij ${ }^{4,7}$
}

Published online: 24 September 2021

๑) Springer-Verlag GmbH Germany, part of Springer Nature 2021

Correction to: Neuroradiology (2021

https://doi.org/10.1007/s00234-021-02746-3

"-Technical" should not appear in 11 text subheadings and has been removed to the start of the proceeding paragraphs.

The original article has been corrected.

Publisher's note Springer Nature remains neutral with regard to jurisdictional claims in published maps and institutional affiliations.

The original article can be found online at https://doi.org/10.1007/ s00234-021-02746-3.

Hugh G. Pemberton

h.pemberton@ucl.ac.uk

1 Centre for Medical Image Computing (CMIC), Department of Medical Physics and Bioengineering, University College London, London, UK

2 UCL Queen Square Institute of Neurology, University College London, London, UK

3 Dementia Research Centre, UCL Queen Square Institute of Neurology, University College London, London, UK

4 Department of Radiology and Nuclear Medicine, Erasmus MC University Medical Center, Rotterdam, The Netherlands

5 Clinical, Educational and Health Psychology, University College London, London, UK

6 Radiology \& Nuclear Medicine, VU University Medical Center, Amsterdam, The Netherlands

7 Department of Epidemiology, Erasmus MC University Medical Center, Rotterdam, The Netherlands 